\title{
The Effects of Temperature and Hydrogen Partial Pressure on Hydrocracking of Phenanthrene
}

\author{
Zhaoxiang Yu, Liang Chen, Zhaowang Zong, Zhirong Zhu \& Qian Wu (Corresponding author) \\ Department of Chemistry, Tongji University, Shanghai 200092, China \\ Tel: 86-21-6598-7939 E-mail: wuqian@tongji.edu.cn
}

Received: December 27, 2010 Accepted: January 19, 2011 doi:10.5539/ijc.v3n2p67

\begin{abstract}
The effects of temperature and hydrogen partial pressure on hydrocracking behavior of phenanthrene were investigated using Mo-mordenite catalyst. It was observed that phenanthrene conversion as well as benzene yield increased with reaction temperatures while xylene yield declined under elevated temperature. In addition, hydrogen partial pressure initiated negligible impacts on both benzene yield and xylene yield, however, the dependence of phenanthrene conversion on temperature varied with hydrogen partial pressure.
\end{abstract}

Keywords: Hydrocracking, Phenanthrene, Mordenite catalyst

\section{Introduction}

Hydrocracking process is usually employed in petroleum refining process for converting heavy oil feedstocks into high quality lighter products such as gasoline, naphtha, jet fuel, diesel fuel and hydrowax which can be used for petrochemical feedstock or lube basestock. With the improvements in process optimization and upgraded zeolite catalyst activity, hydrocracking process has been extended to other applications, such as fluid catalytic cracking cycle oils, coke gas oil and deasphalted oil.

The hydrocracking reaction kinetics and mechanism of polycyclic aromatic compounds have been extensively studied (Reddy, 1996; Benazzi, 2003; Isoda, 1998; Ali. S. H, 2005). Matsui et al. found that the catalytic position of hydrogenation and cracking activity were strongly dependent on nickel-loaded zeolite catalyst pore sizes with hydrogen partial pressure at $70 \mathrm{~kg} / \mathrm{cm}^{2}$ and temperature at $350^{\circ} \mathrm{C}$ (Matsui, 1995), similar results were also reported in Nomura's studies, which indicated the strong relationship of product distribution with zeolite pore size based on the compute aided molecule design studies on three zeolites: ZSM-5, Mordenite and Y-type (Nomura, 1996). Wada et al. investigated the hydrocracking of phenanthrene by using Ni-loaded, Pd-loaded, and $\mathrm{Ni} / \mathrm{Pd}$ co-loaded Y-type zeolite catalysts with hydrogen partial pressure at $30-70 \mathrm{~kg} / \mathrm{cm}^{2}$ and temperature at $325-350^{\circ} \mathrm{C}$, the results demonstrated that the reaction temperature was very critical to affecting product distribution (Wada, 1996). The importance of temperature to the hydrocracking performance of phenanthrene was also pointed out by Leite et al. (2001). Chareonpanich et al. also investigated the hydrocracking of several aromatic hydrocarbons over USY-zeolite under relatively high hydrogen partial pressures and reaction temperatures, and reported a superior hydrocracking activity of USY-zeolite witho nearly $100 \%$ accumulated yields of benzene, toluene and xylene along with negible generation of coke and tar (Chareonpanich, 1996).

Large quantity of phenanthrene can be produced from traditional coal carbonization process, while phenanthrene is always less efficiently utilized to produce carbon black, jet fuel and preservatives for timber etc. chemicals at the price of increased environmental pollution. Accordingly, it would be more valuable to optimize the conversion efficiency of phenanthrene through hydrocracking process to produce benzene, toluene, and xylene (BTX) etc high valuable chemicals. This paper intended to investigate the influence of various temperatures and hydrogen partial pressures on the hydrocracking efficiency of phenanthrene as well as the yields of BTX.

\section{Experimental}

\subsection{Mo loaded mordenite catalyst Preparation}

The mordenite catalyst was synthesized with mordenite, $\mathrm{Al}_{2} \mathrm{O}_{3}$ and nitric acid followed by extruding to band-form and drying at $120^{\circ} \mathrm{C}$ and air calcinations at $550^{\circ} \mathrm{C}$. Mo loading process was initiated by adding $8 \mathrm{~g}$ mordenite catalyst support into $10 \mathrm{ml}$ aqueous solution of $\mathrm{Mo}\left(\mathrm{NiO}_{3}\right)_{2} \cdot 6 \mathrm{H}_{2} \mathrm{O}$ with stirring at $90^{\circ} \mathrm{C}$ for $24 \mathrm{~h}$ to deposit Mo by cationic exchange approach. The molybdenum cation-substituted catalyst was hence obtained 
after filtration and drying at $120^{\circ} \mathrm{C}$. The catalyst was calcined in a stream of air at $550^{\circ} \mathrm{C}$ for $4 \mathrm{~h}$ prior to hydrocracking experiments. The characterization of catalyst sample was performed by chemical analysis, X-ray diffraction, and nitrogen adsorption (10-13). The synthesized Mo-loaded mordenite catalyst contained $8 \mathrm{wt} \%$ Mo, and $18 \AA$ in pore diameter, $308 \mathrm{~m}^{2} / \mathrm{g}$ in surface area, and $0.165 \mathrm{~cm}^{3} / \mathrm{g}$ in pore volume.

\subsection{Apparatus}

Hydrocracking reactions were performed in a fixed bed reactor with gas and liquid sample collectors. The reactor was made of SUS-316 tube $(\Phi 14 \mathrm{~mm})$. Reaction temperature was selected in the range of 370 to $470^{\circ} \mathrm{C}$ and hydrogen partial pressure was selected in the range of 30 to $55 \mathrm{~kg} / \mathrm{cm}^{2}$ with constant hydrogen flowrate at $100 \mathrm{sccm}$. In order to facilitate the feeding of phenanthrene into reactor, phenanthrene was first dissolved in toluene to make a $15.39 \mathrm{wt} \%$ phenanthrene/toluene solution and approached a molar ratio of $\mathrm{H}_{2} /$ phenanthrene at 20.

\subsection{Hydrocracking reaction procedures}

$5 \mathrm{~g} \mathrm{Mo} /$ mordenite catalyst was loaded into reactor followed by pressurizing reactor with hydrogen to specific experimental conditions. The reactor temperature was increased from 20 to $150^{\circ} \mathrm{C}$ at a rate of $5^{\circ} \mathrm{C} / \mathrm{min}$, from 150 to $350^{\circ} \mathrm{C}$ at $4^{\circ} \mathrm{C} / \mathrm{min}$, and from $350^{\circ} \mathrm{C}$ to target temperature between 370 and $470^{\circ} \mathrm{C}$ at $2^{\circ} \mathrm{C} / \mathrm{min}$. It was assumed that the reaction was initiated when temperature reached the temperature setpoint.. Liquid product was analyzed by a gas chromatograph (Hewlett Packard 5890II) equipped with a 15 m length PONA column (DB-1 capillary column, $\Phi 0.53 \mathrm{~mm})$. The column temperature was controlled at $70^{\circ} \mathrm{C}$ for $5 \mathrm{~min}$ and then heated to $270^{\circ} \mathrm{C}$ at a heating rate of $20^{\circ} \mathrm{C} / \mathrm{min}$. The species of hydrocracking products were identified by GC-MS analysis.

\section{Results and discussion}

\subsection{Hydrogenation reaction of phenanthrene}

The hydrogenation reaction rate of phenanthrene is relatively high and hydrogenation efficiency could approach completion with Di- and tetrahydrophenanthrene as the primary products and sym- or asym-octahydrophenanthrene and isotetrahydrophenanthrene as the possible secondary products (Korre, 1997). On the other hand, the conversion of phenanthrene to perhydrophenanthrene seems difficult due to the sterical hinderation of the central ring. The hydrogenation sequence of phenanthrene is: phenanthrene $\rightarrow$ dihydrophenanthrene $\rightarrow$ tetrahydrophenanthrene $\rightarrow$ octahydrophenanthrene. Since the first two steps of hydrogenation of polycyclic aromatic hydrocarbons is more rapid than the third one and the cracking of the side ring is more difficult, it seems that further cracking occurs preferentially on the central ring.

Fig. 1. Hydrogenation reaction network of phenanthrene.

\subsection{Hydrocracking reaction of phenanthrene}

The hydrocracking products of phenanthrene is very complex which might involve over seventy species. Both temperature and hydrogen partial pressure have significant impacts on the product distribution. The liquid products primarily include benzene, toluene, xylene, trimethylbenzene, and negligible dihydrophenanthrene and methylphenanthrene as well. Based on the qualitative analysis, the hydrocracking pathway can be depicted as following:

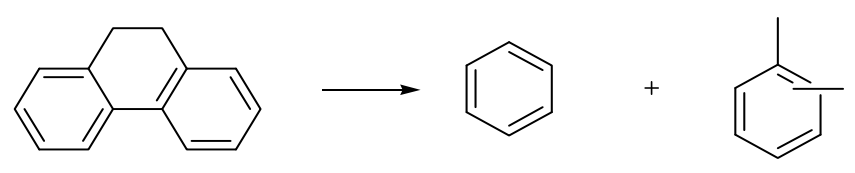

The presence of toluene solvent in reactant inhibits the conversion of phenanthrene to toluene, while toluene could be catalytically converted to benzene and xylene in the presence of mordenite catalyst as described in equation 2. Accordingly, the BTX products in this study were primarily composed of benzene and xylene.

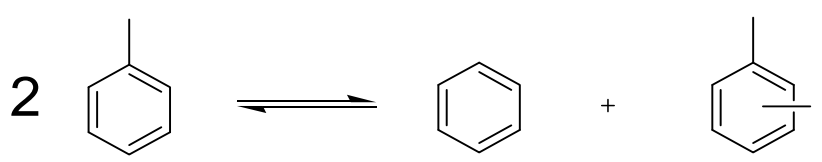

The calculations of phenanthrene conversion and BTX yields can be expressed in equations (3-5): 


$$
\begin{gathered}
\mathrm{X}_{\text {phe }}=\frac{m_{0}-m_{1}}{m_{0}} \times 100 \% \\
\mathrm{Y}_{\text {ben }}=\frac{m_{b e n}}{m_{0}} \times 100 \% \\
\mathrm{Y}_{\mathrm{xyl}}=\frac{m_{\mathrm{xy} 1}}{m_{0}} \times 100 \%
\end{gathered}
$$

where $m_{0}$ and $m_{1}(\mathrm{~g})$ are the phenanthrene feed and phenanthrene residual in mass weight $(\mathrm{g})$ respectively, $m_{\text {ben }}$ and $m_{\mathrm{xyl}}$ are the mass weight of benzene and xylene $(\mathrm{g})$, respectively.

\subsection{Effects of temperature on the reaction kinetics}

\subsubsection{Phenanthrene Conversion}

The influence of reaction temperature on phenanthrene conversion under various hydrogen partial pressures (3.5 $-5.5 \mathrm{MPa}$ ) was shown in Figure 2, indicating a considerable dependence of phenanthrene conversion on reaction temperature. Significant increases in phenanthrene conversion can be observed when temperature was increased from 410 to $430^{\circ} \mathrm{C}$, possibly due to the catalyst activity enhanced with temperature above $410^{\circ} \mathrm{C}$. However, the further increases in temperature above $430^{\circ} \mathrm{C}$ under hydrogen partial pressure over $4.0 \mathrm{MPa}$ led to little changes in phenanthrene conversion. According to the Arrhenius equation, reaction rate constant increases with temperature. Since the reaction volume increases, the raise of hydrogen partial pressure is adverse to the positive reaction. As a result, the efficiency of phenanthrene conversion was considerably impacted on both temperature and hydrogen partial pressure. At higher hydrogen partial pressures, temperature was a dominant factor leading to increased conversion at elevated temperature, but the trend was leading to nearly constant phenanthrene conversion even further increasing temperature.

Fig. 2 Phenanthrene conversion as a function of temperature under various hydrogen partial pressures.

\subsubsection{Benzene yield}

The relationship of benzene yield with reaction temperature under various hydrogen partial pressures was shown in Figure 3, which demonstrated a low level of benzene yield in the temperature range of $370-410^{\circ} \mathrm{C}$, while benzene yield increased to above $30 \%$ with temperature over $420^{\circ} \mathrm{C}$, possibly due to the low phenanthrene conversion at lower temperature and a sharp increase in phenanthrene conversion during the temperature region between $410-430^{\circ} \mathrm{C}$, evidenced by a sharp change in catalyst activity around $410^{\circ} \mathrm{C}$. In addition, temperature impacts on benzene yield was fluctuated more significant at low hydrogen partial pressure than at high pressure.

Fig. 3. Benzene yield as a function of temperature under various hydrogen partial pressures on the Mo-loaded mordenite catalyst.

\subsubsection{Xylene yield}

Fig. 4 showed the yield of xylene versus temperature under various hydrogen partial pressures. It was also observed that a low level xylene yield appeared in the low temperature region similar as the performance of benzene yield, however, xylene yield decreased with increasing temperature. When temperature increased to above $430^{\circ} \mathrm{C}$, xylene yields under some conditions turned to negative. As shown in eq 2 . the cracking of dihydrocrackphenanthrene can form equimolar benzene and xylene, which was in agreement with the observed benzene yield at $370^{\circ} \mathrm{C}$ (Figure 3). The phenomenon of xylene yield changing with reaction temperature in the opposite direction as benzene yield changing with temperature was due to the further disproportionation of xylene after phenanthrene hydrocracking with a relatively higher conversion rate than the generation rate of xylene. Again, similar as benzene yield, temperature impacts on xylene yield fluctuated more obvious at low hydrogen partial pressure than at high hydrogen partial pressure.

Fig. 4. Xylene yield as a function of temperature under various hydrogen partial pressures on the Mo-loaded mordenite catalyst.

\subsection{Effect of hydrogen partial pressure on reaction kinetics}

\subsubsection{Phenanthrene conversion}

The effects of hydrogen partial pressure on phenanthrene conversion at the temperature range of $370-450^{\circ} \mathrm{C}$ was shown in Figure 5. It can be observed that the impacts of hydrogen partial pressures on phenanthrene conversion varied with temperature. At low temperature range, the conversion was initially slightly increase and 
then decreased gradually. The trends showed in the Fig. 5 were in agreement with that we proposed above.

Fig. 5. Phenanthrene conversion as a function of hydrogen partial pressure at various temperatures on the Mo-loaded mordenite catalyst.

\subsubsection{Benzene yield}

Fig. 6 showed the yield of benzene versus hydrogen partial pressure at various temperatures. It again demonstrated that benzene yield changed with hydrogen partial pressure differently at different temperatures. The low catalyst activity at temperature below $410^{\circ} \mathrm{C}$ obviously generated low benzene yield, thus leading to no immediate relationship between benzene yield and hydrogen partial pressure. However, the enhanced catalyst activity at temperature above $430^{\circ} \mathrm{C}$ can apparently lead to higher benzene yield. In addition, although hydrogen partial pressure could significantly impact catalyst activity, however, since catalyst activity turned more stable at temperature above $430^{\circ} \mathrm{C}$, thus the effects of hydrogen partial pressure on benzene yield diminished leading to negligible changes in benzene yield.

Fig. 6. Benzene yield as a function of hydrogen partial pressure at various temperatures on the Mo-loaded mordenite catalyst.

\subsubsection{Xylene yield}

The relationship of hydrogen partial pressures with xylene yield at various temperatures was shown in Figure 7, indicating little changes in xylene yield with changing hydrogen partial pressure. This phenomenon might be attributed to the different magnitude of hydrogen partial pressure impacts on hydrocracking of phenanthrene and disproportionation of xylene. At low hydrogen partial pressure, xylene conversion rate was relatively lower than its generation rate, and the yield increased with hydrogen partial pressure. However, xylene conversion significantly increased with hydrogen partial pressure higher than $4.0 \mathrm{MPa}$ thus leading to decreased xylene yield.

Fig. 7. Xylene yield as a function of hydrogen partial pressure at various temperatures on the Mo-loaded mordenite catalyst.

\section{Conclusion}

The effects of temperature and hydrogen partial pressure on phenanthrene conversion and benzene and xylene yield were investigated via phenanthrene hydrocracking reaction on Mo-loaded mordenite catalyst. The effects of temperature on phenanthrene conversion at different hydrogen partial pressures were similar, while hydrogen partial pressure impacted phenanthrene conversion differently with changing temperatures. The same phenomenon was observed on benzene yield except that xylene yield decreased with temperature and remand little changed at different hydrogen partial pressure, possibly due to the effect of hydrogen partial pressure on both hydrocracking of phenanthrene and disproportionation of xylene. Accordingly, further investigations will be focused on the relationship between conversion rate and generation rate of xylene.

\section{References}

Ali. S. H., Al-Mutairi. F., Fahim. M. (2005). Solubility of polycyclic aromatics in binary solvebt mixtures using activity coefficient models. Fluid Phase Equilibria, 230, 176-183.

Benazzi. E., Leite. L., Macchal-George. N., Toulhoat. H., Raybaud. P. (2003). New insights into parameters controlling the selectivity in hydrocracking reactions. Journal of Catalysis, 217, 376-387.

Chareonpanich. M., Zhang. Z-G., Tomita. A. (1996). Hydrocracking of Aromatic Hydrocarbons over USY-Zeolite. Energy \& Fuels, 10, 927-931.

Fang. X-C, Guan. M-H., Liao. S-G. (2008). Hydrocracking. (1st ed). Beijng, (Chapter 2).

Isoda. T., Kusakabe. K., Morooka. S., Isao. M. (1998). Reactivity and Selectivity for the Hydrocracking of Vacuum Gas Oil over Metal-Loaded and Dealuminated Y-zeolites. Energy \& Fuels, 12, 493-502.

Korre. S. C., Klein. M. T., Quann. R. J. (1997). Hydrocracking of Polynuclear Aromatic Hydrocarbons. Development of Rate Laws through Inhibition Studies. Ind. Eng. Chem. Res., 36, 2041-2050.

Leite. L., Benazzi. E., Marchal-George. N. (2000). Studies in Surface Science and Catalysis, 130, 2495.

Leite. L., Benazzi. E., Marchal-George. N. (2001). Hydrocracking of phenanthrene over bifunctional Pt catalysts. Catalysis Today, 65, 241-247.

Matsui. H., Akigi. K., Murate. S., Nomura. M. (1995). Explanation of Product Distribution of Hydrocracking Reaction of Aromatic Hydrocarbons with Nickel-Loaded Zeolita Based on CAMD Study on Interaction between 
Zeolite and Substrates. Energy \& Fuels, 9, 435-438.

Nomura. M., Akagi, K., Murata. S., Matsui. H. (1996). Hydrocracking of polycyclic aromatic compounds using zeolite catalysts: Explanation of product distribution based on a computer aided molecular design study on the interaction of zeolite and substrates. Catalysis Today, 29, 235-240.

Reddy. K. M., Song. C-S. (1996). Synthesis of mesoporous zeolites and their application for catalytic conversion of polycyclic aromatic hydrocarbons. Catalysis Today, 31, 137-144.

Sarbak. Z. (2001). NiMo catalysts supported on anion modified zeolites type Y-structural properties and HDS activity. Applied Catalysis A: General, 216, 9-12.

Sarbak. Z., Lewandowski. M. (2001). Catalytic elimination of nitrogen organic compounds from the coal-liquid and structural properties of NiMo catalysts supported on $\mathrm{NaX}$ and $\mathrm{NaY}$ zeolites modified with transition metal cations. Applied Catalysis A: General, 208, 317-321.

Wada. T., Kaneda. K., Murate. S., Nomura.M. (1996). Effect of modifier Pd metal on hydrocracking of polyaromatic compounds over Ni-loaded Y-zeolite and its application as hydrodesulfurization catalyst. Catalysis Today, 31, 113-120.<smiles>c1ccc2ccccc2c1</smiles>

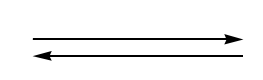<smiles>c1ccc2c(c1)CCc1ccccc1-2</smiles>
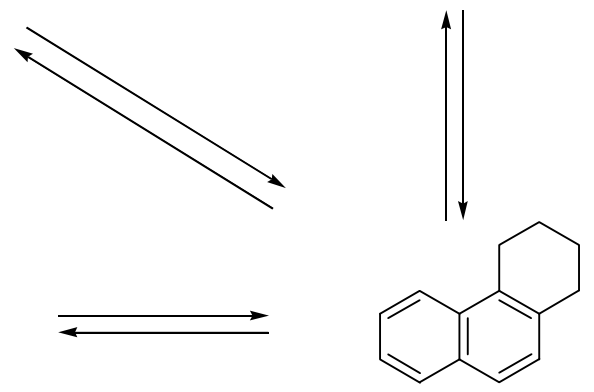

Figure 1. Hydrogenation reaction network of phenanthrene
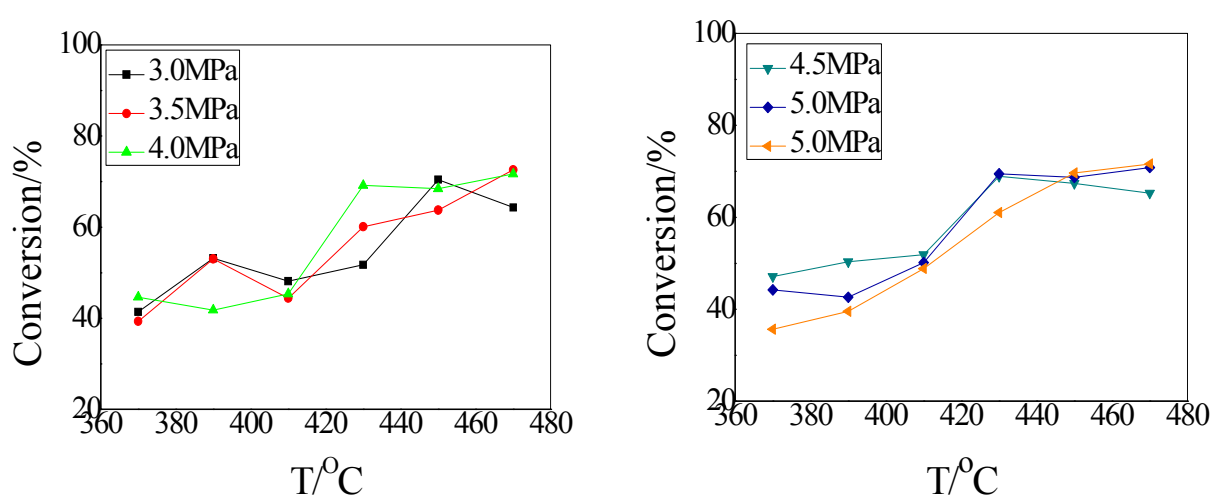

Figure 2. Phenanthrene conversion as a function of temperature for the studied hydrogen partial pressures on the Mo-loaded mordenite catalyst 

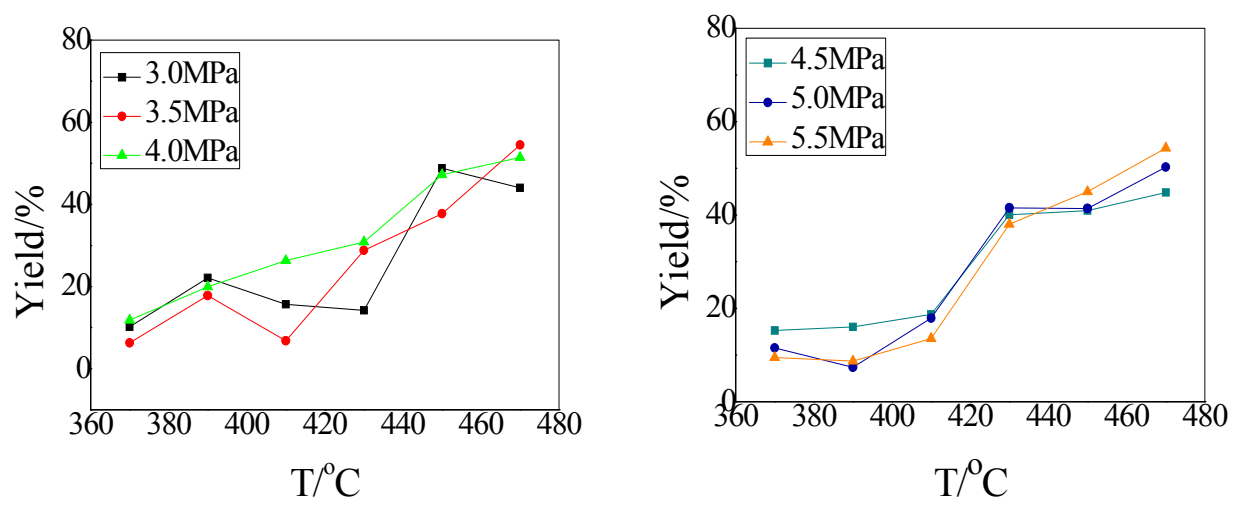

Figure 3. Benzene yield as a function of temperature for the studied hydrogen partial pressures on the Mo-loaded mordenite catalyst
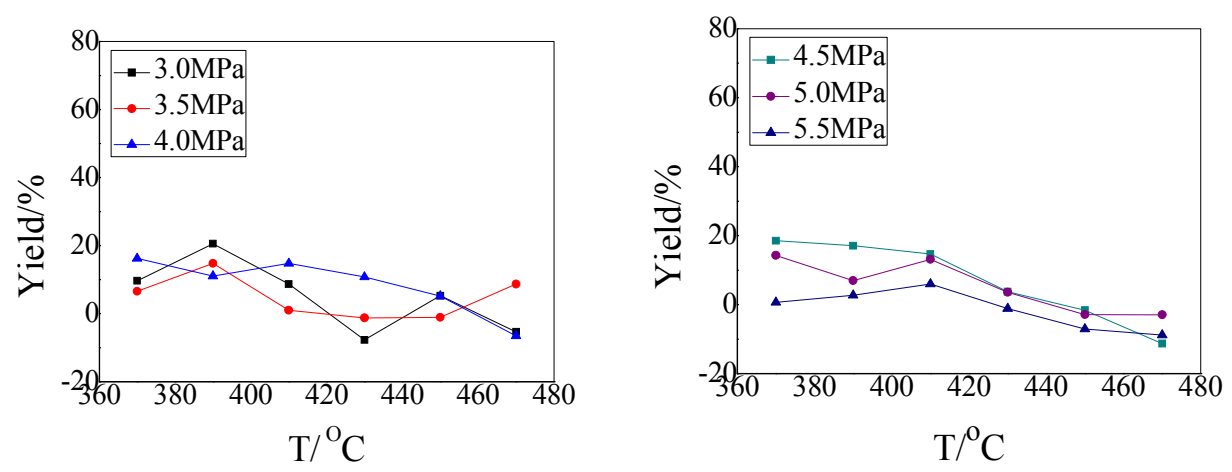

Figure 4. Xylene yield as a function of temperature for the studied hydrogen partial pressures on the Mo-loaded mordenite catalyst
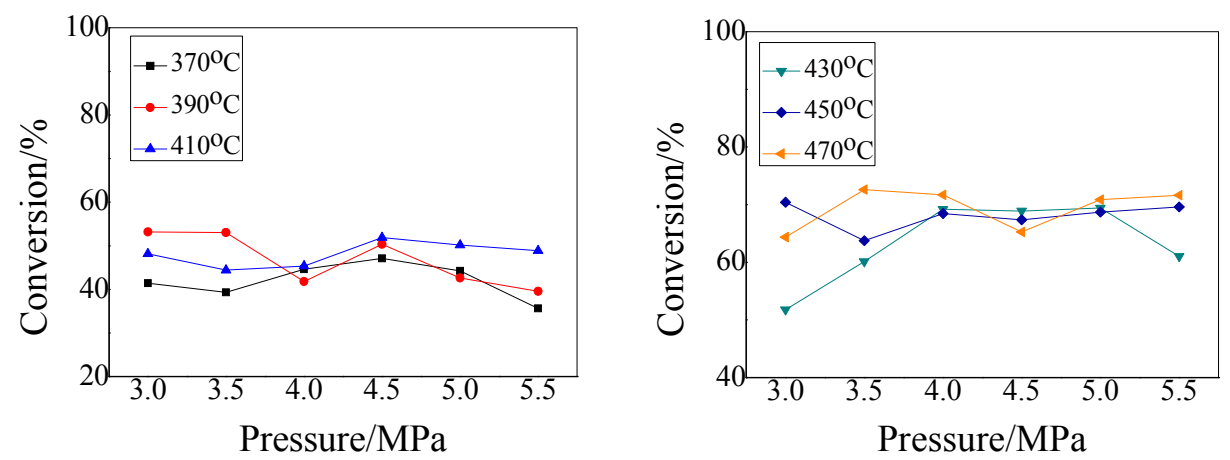

Figure 5. Phenanthrene conversion as a function of hydrogen partial pressure for the studied temperatures on the Mo-loaded mordenite catalyst 

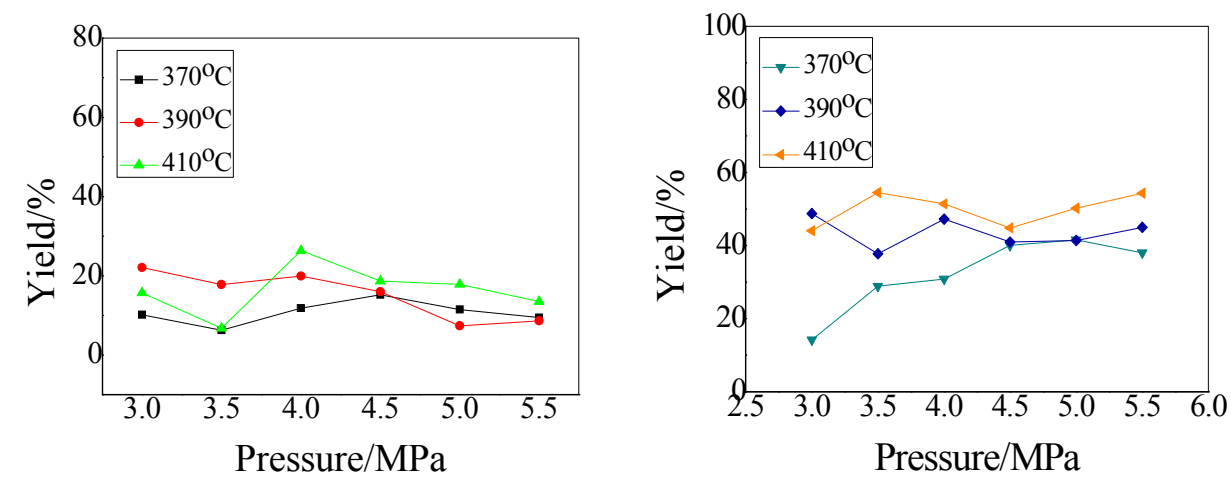

Figure 6. Benzene yield as a function of hydrogen partial pressure for the studied temperatures on the Mo-loaded mordenite catalyst
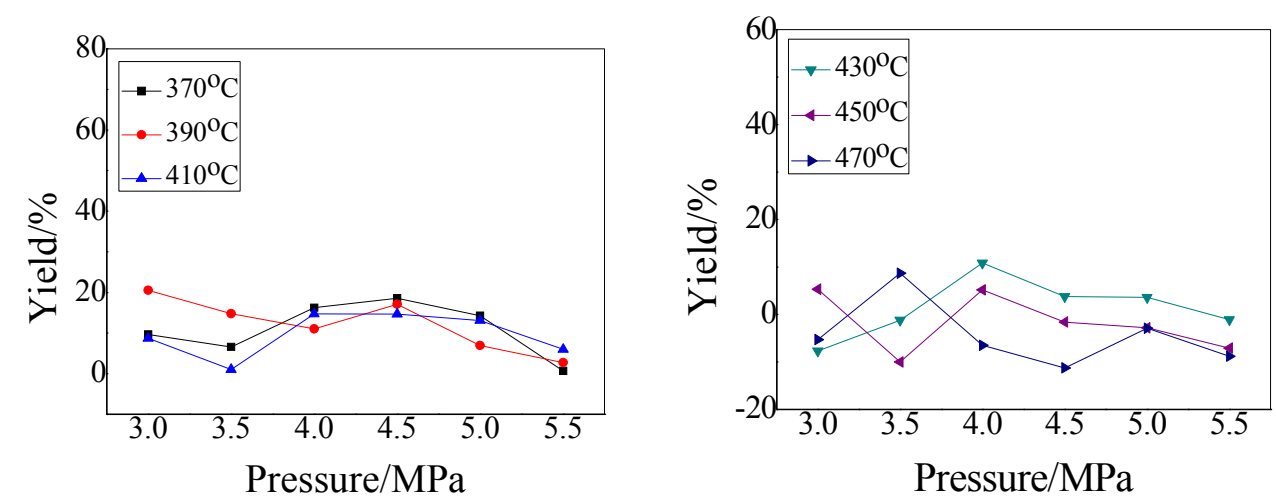

Figure 7. Xylenee yield as a function of hydrogen partial pressure for the studied temperatures on the Mo-loaded mordenite catalyst 